\title{
INTRODUÇÃO AO MÉTODO DE PESQUISA DAS PAIXÕES "TÓXICAS": DO RACIOCÍNIO POR ANALOGIA À SEMIOLOGIA PSICANALÍTICA ${ }^{1}$
}

\author{
Victor Eduardo Silva BENTO2
}

- RESUMO: Tratou-se de pesquisa de revisão crítica da literatura no campo da epistemologia. Partiu-se da hipótese das paixões "tóxicas", isto é, de que existe uma analogia funcional entre as paixões e as toxicomanias devido à função do excesso narcísico, semelhante, mas não idêntica, em ambas. O objetivo foi introduzir os fundamentos teóricos dos métodos de pesquisa qualitativa desta hipótese, partindo-se do raciocínio por analogia na direção da semiologia psicanalítica. Mais precisamente, pretendeu-se discutir, em nível introdutório, alguns fundamentos teóricos destes métodos vistos como análogos, com dupla finalidade: equacionar uma formulação da hipótese das paixões "tóxicas" de acordo com estes métodos; e estruturar um plano de estudo teórico de caráter psicanalítico, em debate interdisciplinar, adequado a esta formulação, a ser executado em outras investigações a partir da aplicação destes métodos na pesquisa desta hipótese.

- PALAVRAS-CHAVE: Epistemologia; método de pesquisa qualitativa; raciocínio por analogia; semiologia psicanalítica; paixões tóxicas.

1 Este artigo foi retirado da Tese de Doutorado em Psicopatologia Fundamental e Psicanálise, ainda não publicada, do autor do presente trabalho, intitulada: La passion amoureuse "toxique": une approche psychanalytique à partir de la sémiologie et du narcissisme chez Freud (Bento, 1996). Por se tratar de tese realizada na Universidade Paris 7, suas citações e idéias estão todas escritas em língua francesa. Em função desta particularidade, decidiu-se dar o seguinte tratamento às citações e às idéias desta tese retomadas neste trabalho:

1.1. As citações das obras em francês foram traduzidas para o português pelo autor, quando não foi possível substituí-las por suas correspondentes traduções em edições em português das obras citadas.

1.2. Mesmo tendo sido retirado de Bento (1996), o presente estudo avança em relação a este trabalho, acrescentando, assim, novos dados de pesquisa bibliográfica, muitos deles retirados da literatura francesa (receberão o mesmo tratamento acima especificado no item 1.1), novas articulações, novas questões, novas hipóteses, novas precisões conceituais, etc.

2 Psicólogo, Doutor em Psicopatologia Fundamental e Psicanálise pela Universidade Paris 7; Professor do Departamento de Psicometria do Instituto de Psicologia da UFRJ. Artigo recebido em 03/ 2009 e aprovado em 05/2009. 


\section{Introdução}

Trata-se aqui de uma pesquisa de revisão crítica da literatura no campo da epistemologia. Como seu título sugere, parte-se neste trabalho do pressuposto hipotético das paixões "tóxicas", isto é, de que existe uma analogia funcional entre as paixões e as toxicomanias devido à função do excesso narcísico, semelhante, mas não idêntica, em ambas. O título também sugere o objetivo deste artigo: introduzir os fundamentos teóricos dos métodos de pesquisa qualitativa desta hipótese das paixões "tóxicas", partindo da abordagem do raciocínio por analogia na direção da semiologia psicanalítica. Mais precisamente, pretende-se discutir, em nível introdutório, os seguintes pontos: $1^{\circ}$ Alguns fundamentos teóricos do método de pesquisa do raciocínio por analogia, $2^{\circ}$ Alguns fundamentos teóricos do método de pesquisa semiológica, e $3^{\circ} \mathrm{O}$ método de pesquisa da hipótese das paixões "tóxicas", do raciocínio por analogia à semiologia psicanalítica. A finalidade neste terceiro e último ponto será dupla: por um lado, equacionar uma formulação desta hipótese de acordo com estes métodos; e, por outro, estruturar um plano de estudo teórico de caráter psicanalítico, em debate interdisciplinar, adequado a esta formulação, a ser executado em outras investigações a partir da aplicação destes métodos na pesquisa da mesma hipótese.

\section{Alguns fundamentos teóricos do método de pesquisa do raciocínio por analogia}

Quando o pesquisador põe-se a observar a maneira pela qual a literatura acadêmica trata a "analogia", apercebe-se de que o termo aparece aplicado a diversos domínios, revestido de uma grande diversidade de sentidos, fazendo-se objeto de uma crítica severa por parte dos lógicos e dos epistemólogos. Estes costumam, em geral, desvalorizar a maior parte dos empregos deste vocábulo porque os consideram vagos e desprovidos de rigor científico. A única exceção ocorre apenas em relação ao sentido original da analogia entre os gregos, especialmente em Aristóteles. De fato, a significação deste termo parece ter involuído de um uso preciso - em Platão e em Aristóteles -, que o relacionava ao sentido da proporção matemática (igualdade de funções), até um uso corrente e impreciso que lhe dava o sentido de semelhança, sentido este visto como oposto àquele sentido primitivo do termo. De fato, este sentido preciso original situa-se mais além da mera semelhança e remete ao chamado "raciocínio por analogia", a única forma de analogia verdadeiramente rigorosa e adequada do ponto de vista científico, metodológico e lógico. A este respeito, Lalande escreverá: 


\section{ANALOGIA}

A. Sentido primitivo e próprio: identidade da relação que une dois a dois os termos de dois ou mais pares. Especialmente, e por excelência, proporção matemática [...]. ARISTÓTELES analisa este sentido com precisão na Ética a Nicômaco, V, 6; $113^{\mathrm{a} 30 \text { ss. [...] }}$

E. Sentido corrente e vago: semelhança mais ou menos distante, particularmente entre as coisas que não se assemelham no seu aspecto geral e não podem ser subsumidas sob um mesmo conceito. [...]

\section{Raciocínio por analogia}

A. Raciocínio fundado sobre a analogia no sentido A. Em particular, determinação de um termo pelo conhecimento dos dois termos de um dos pares e de um dos termos do segundo.

B. Todo raciocínio que conclui em virtude de uma semelhança entre os objetos sobre os quais se raciocina.

\section{CRÍTICA}

Esta expressão, afora o sentido A, de que o cálculo da "quarta proporcional" é o tipo, representa uma ideia muito vaga, que se tornou ainda mais confusa com a tentativa de torná-la precisa em diversos sentidos (Lalande, 1926/1996, p. 62-63). Ver passagem correspondente na edição francesa. (Lalande, 1926/1993, p. 51-52)

Este ponto de vista de Lalande (1926/1996, 1926/1993) parece ser compartilhado por Secretan quando este autor escreve:

\section{ANALOGIA E RACIONALIDADE CIENTÍFICA}

A agregação da analogia à racionalidade científica foi marcada pelas três desgraças da rejeição, da hesitação e das mutilações. Rejeição em primeiro lugar, o termo "analogia" sendo desvalorizado - no uso corrente - em uma semelhança vaga, incompatível com o rigor científico, inimigo de todo e qualquer equívoco. Com o triunfo do nominalismo, a univocidade lógica o dominou amplamente sobre a analogicidade metafísica. Hesitação todavia, porque existe na analogia - e especialmente no raciocínio por analogia - uma nota lógica ou metodológica que talvez não seja desprezável, uma vez que se trata sobretudo de assimilar ao conhecido dos domínios cada vez mais estranhos as estruturas já teoretizadas. O valor das semelhanças funcionais ou estruturais seria então por sua vez explorável sob o termo global "analogia". Mas mutilação, na exata medida em que a analogia é reduzida a uma semelhança, enquanto não é aí que reside a "razão" da analogia. Dito de outra maneira, é a proporção que vem a faltar como portadora de ana-logicidade. (Secretan, 1984, p. 89; tradução nossa)

A pesquisa de Dorolle (1949) chega a conclusões idênticas, pois ele valoriza o "raciocínio por analogia" em Aristóteles, de um lado, e, de outro, desvaloriza o sentido "vago" que restringe a analogia à simples semelhança, uma redução que ele qualifica em seu prefácio como procedimento de inferência dos mais perigosos e condenados ao erro. Este autor também esclarece em seu prefácio qual seria seu verdadeiro objetivo: definir este modo de raciocínio e, a partir daí mesmo, situá-lo entre as formas do traba- 
lho intelectual; e buscar saber a quais funções ele responde, no desenvolvimento geral do pensamento e da ciência.

No livro de Dorolle (1949), inteiramente dedicado ao raciocínio por analogia, pode-se encontrar uma primeira parte que se destina à abordagem da natureza e da definição deste raciocínio. Seu primeiro capítulo trata apenas da "analogia em Aristóteles" como "a forma mais precisa, e, sem dúvida, a partir daí, o ponto de partida lógico da noção de analogia [...] na ideia de uma igualdade de funções no sentido matemático" (p. 1), e, mais precisamente, no sentido da "proporção geométrica: A : B :: C : D" (p. 5) (traduções nossas). Em ":" deve-se ler "está para", e "::" significa "assim como".

Dorolle (1949) prossegue mostrando a evolução dessa ideia de proporção que chega a ser aplicada "à expressão de fatos psicobiológicos, e às noções morais" (p. 6), representando, assim, uma "passagem deste sentido quantitativo da analogia ao sentido qualitativo de uma semelhança de funções, por onde se chega a um emprego sempre preciso, mas infinitamente amplo do termo" (p. 7), e onde este, "ao invés de ser igualdade, se torna semelhança de funções" (p. 7). O exemplo citado aqui como o mais típico e o mais conhecido é aquele da "analogia de função que Aristóteles estabelece entre os pulmões e as brânquias": "os animais que vivem dentro da água utilizam as brânquias como os animais de respiração aérea (utilizam) os pulmões: Pulmão : Ar :: Brânquias : Água" (p. 9) (as traduções são nossas). Deve-se ler: o Pulmão está para o Ar, assim como as Brânquias estão para a Água. Obviamente, a função semelhante neste exemplo é a respiração, seja ela através dos pulmões nos animais terrestres, ou das brânquias nos animais aquáticos.

A propósito desse exemplo, Dorolle (1949) insistirá na oposição entre "simples ou vagas semelhanças, e estas posições mais precisas de semelhanças de funções" (p. 9), e evocará ainda a figura da metáfora que, sendo um raciocínio por analogia, também será precisa, já que "ela faz ver uma coisa mental sob a mesma função de um fato ou de uma coisa material" (p. 9) (traduções nossas).

Dorolle (1949) afirma ainda que o raciocínio por analogia implica importantes funções: por um lado, aquela de inovação, de criação, por meio da descoberta de uma semelhança escondida (a semelhança de funções) e, por outro lado, aquela de generalização, de constituição de conceitos, que se situa no campo da teorização sistemática, da explicação. A propósito desta primeira função, Dorolle escreverá:

Mas isto mesmo já é bem a forma de um raciocínio, de um movimento do pensamento que, a partir de uma semelhança de funções, conclui uma ideia nova. Aristóteles descreve assim com uma exatidão notável o que fez a sua própria força, e sem dúvida uma das características essenciais de seu pensamento. Gomperz faz, 
com efeito, observar, utilizando mesmo expressões de Aristóteles, que "a sagacidade não se revela em nenhum outro lugar num grau mais elevado que na descoberta das semelhanças escondidas". [...] O raciocínio por analogia permite, com efeito, ultrapassar sem cessar uma experiência ainda insuficiente, já que, partindo de coisas que estão numa mesma função (relação), e se distinguindo a partir daí do raciocínio que se apoia nas semelhanças de propriedades de um assunto (1), ele vai mais além dos assuntos dados para afirmar as propriedades que permanecem não observadas, ou, então, partindo da constatação da semelhança de funções (ou relações), ele estende a uma segunda relação a conclusão válida para uma primeira. (Dorolle, 1949, p. 11-12; tradução nossa)

Quanto à função analógica de generalização, de constituição de conceitos, Dorolle acrescenta:

Mas, sob um outro aspecto, este uso da analogia, da conclusão de propriedades, e, sobretudo, conclusão de funções, aparece como resultando na constituição de conceitos; ela é então um meio de generalização. [...] Este meio de generalização aplica-se em todos os domínios, tanto na moral (3), quanto na biologia. (Dorolle, 1949, p. 13; tradução nossa)

Se Dorolle começa a primeira parte de seu livro buscando a natureza e a definição do raciocínio por analogia em Aristóteles, ele terminará num quarto e último capítulo desta mesma parte reforçando a associação entre este raciocínio e as analogias de funções (identidade ou semelhança de funções), assim como diferenciando estas últimas das analogias restritas à ideia vaga de simples semelhança. No que concerne ao primeiro aspecto, Dorolle escreverá:

A analogia será, então, ou bem a utilização da ideia de uma função para passar de um terceiro termo (C), que lembra o primeiro (A), a um quarto (D), que lembra o segundo (B), ou bem a utilização da simetria dos termos dois a dois para pôr a ideia de uma função. [...] Em resumo, raciocinar por analogia é tomar como ponto de apoio ou bem uma semelhança de duas relações (ou funções) para concluir disto uma certa semelhança ou mesmo uma identidade de termos, ou bem uma semelhança (superficial) de duas relações (ou funções) para concluir da natureza conhecida (ou suposta) de um dos dois à natureza do outro. (Dorolle, 1949, p. 45-47; tradução nossa)

Para caracterizar melhor ainda o raciocínio por analogia e, ao mesmo tempo, dar os acabamentos finais a sua definição e diferenciá-lo daquilo que poderia ser chamado de "associações" ou de "simples comportamentos por semelhança", isto é, das analogias restritas à ideia de simples semelhança, Dorolle (1949, p. 53) o situará como conjunto de "reações intelectuais", opondo-o àquilo que ele chamará pura e simplesmente de "reações". Dito de outra maneira, o raciocínio por analogia se situaria, assim, mais além de uma analogia vaga (simples semelhança), já que ele a englobaria, porém indo 
mais adiante dela. Ele seria "reação" como uma analogia vaga, mas, mais do que isso, ele seria uma "reação intelectual" (grifos nossos neste parágrafo).

Com a finalidade de precisar essa inteligência do raciocínio por analogia, Dorolle (1946, p. 55-56) destacará a intervenção daquilo que se pode compreender como uma análise histórica. Se as reações (as "associações") em geral (todas as analogias, aqui incluído o raciocínio por analogia) baseiam-se em uma memória, em um passado ("uma expectativa analógica"), as reações intelectuais ultrapassarão esta dimensão projetando-se no futuro, já que elas implicarão a "consciência das razões que extrai do passado os meios para construir o futuro". Compreende-se, assim, que para este autor as simples analogias correspondem às associações impulsivas, às expectativas subjetivas postas em ato (passagem ao ato), em oposição ao raciocínio por analogia que dependeria de uma reflexão consciente considerando o passado, o presente e o futuro. Esse autor escreverá sobre isto:

A ideia de futuro não se situa então em uma expectativa tomada em si mesma. Ela também não é característica do raciocínio analógico. Eis aqui como é. O raciocínio analógico, observa com justiça M. Cresson, demanda que "eu tenha notado" uma "semelhança de circunstâncias". Nós estamos de acordo. Mas isto não significa que uma expectativa analógica, fato essencialmente afetivo em si mesmo, não possa se reduzir às reações por associações; exatamente o que significa é que a consciência vem, em um dado momento, juntar-se a esse mecanismo, e nós dizemos que neste momento aparece o raciocínio propriamente analógico e a inteligência mesma, consciência das razões que extrai do passado os meios para construir o futuro. [...] ele (o raciocínio por analogia) só aparece com seus caracteres próprios com a consciência; a expectativa animal por analogia pode dar um equivalente prático; isto não é, propriamente, um "raciocínio por analogia". (Dorolle, 1949, p. 55-56)

Em resumo, a abordagem de Dorolle (1949) valoriza o raciocínio por analogia, compreendendo-o como preciso, tanto em sua forma quantitativa primitiva (analogia funcional da proporção matemática, a identidade ou igualdade de funções), quanto em sua diversidade de expressões qualitativas (a analogia funcional da semelhança de funções). Quanto às funções deste raciocínio na ciência, este autor destacará aquela da criação pela descoberta de uma semelhança escondida (a semelhança de funções), assim como aquela da generalização, da formação de conceitos, de teorização sistemática. Finalmente, no que concerne ao valor deste mesmo raciocínio, Dorolle (1949) porá em evidência dois fatores que asseguram sua precisão e opõem à analogia vaga e restrita a simples semelhança em sentido corrente: um fator estrutural, sincrônico, sistemático, associado à idéia da analogia de funções; e um fator diacrônico, ligado à importância atribuída à análise da dimensão histórica.

Tendo-se discutido acima alguns dos principais fundamentos teóricos do método de pesquisa do raciocínio por analogia, pode-se passar ao item 
seguinte para analisar alguns dos principais fundamentos teóricos do método de pesquisa semiológica, antes de finalizar este trabalho com a aplicação destes dois métodos na hipótese das paixões "tóxicas", com uma dupla finalidade: $1^{a}$ Equacionar uma formulação desta hipótese de acordo com estes métodos; e $2^{a}$ Estruturar um plano de estudo teórico de caráter psicanalítico, em debate interdisciplinar, adequado a esta formulação, a ser executado em outras investigações a partir da aplicação destes métodos na pesquisa desta hipótese das paixões "tóxicas".

\section{Alguns fundamentos teóricos do método de pesquisa semiológica}

O método semiológico e, particularmente, a semiologia psicanalítica já foram mais detalhadamente estudados em Bento (2006b, 2007a, 2007b). Neste item pretende-se apenas introduzir os principais fundamentos deste método para, no item seguinte, aplicá-lo na abordagem da hipótese das paixões "tóxicas". Pode-se, então, começar afirmando que foi Saussure (1916/ 1995a, 1916/1995b) o pai da semiologia agora em questão, disciplina que surge no campo da linguística estrutural com a seguinte definição:

Pode-se, então, conceber uma ciência que estude a vida dos signos no seio da vida social; ela constituiria uma parte da Psicologia social e, por conseguinte, da Psicologia geral; chamá-la-emos de Semiologia (do grego semeîon, "signo"). Ela nos ensinará em que consistem os signos, que leis os regem. Como tal ciência não existe ainda, não se pode dizer o que será; ela tem direito, porém, à existência; seu lugar está determinado de antemão. A Linguística não é senão uma parte dessa ciência geral; as leis que a Semiologia descobrir serão aplicáveis à Linguística, e esta se achará dessarte vinculada a um domínio bem definido no conjunto dos fatos humanos.

Cabe ao psicólogo determinar o lugar exato da Semiologia (Saussure, 1916/ 1995b, p. 24). Ver passagem correspondente na edição francesa: Saussure. (1916/ 1995a, p. 33)

Para precisar o que chama de "signo", Saussure (1916/1995b, p. 80-81) escreverá: "o signo linguístico une não uma coisa e uma palavra, mas um conceito (significado) e uma imagem acústica (significante)". Além disso, tratar-se-á para este autor de valorizar uma dimensão psíquica, pois, segundo ele, a imagem acústica "não é o som material, coisa puramente física, mas a impressão [empreinte] psíquica desse som, a representação que dele nos dá o testemunho de nossos sentidos". É o que fará da semiologia, esta ciência dos signos, uma psicologia. A Semiologia, escreve Saussure (1916/ 1995b, p. 24), "constituiria uma parte da Psicologia social e, por conseguinte, da Psicologia geral". 
E, para detalhar aquilo que Saussure (1916/1995b, p. 24-25) chama de "social", de "vida social", esse autor evocará "um domínio bem definido no conjunto dos fatos humanos", ilustrando-os pelos "ritos, os costumes etc."

Quanto à "Semiologia Psicanalítica", pode-se encontrar uma proposição sobre esta em Bento (2007a), inspirada inicialmente na semiologia da linguística de Saussure. Depois de Saussure, a outra inspiração de Bento (2007a) para a sua proposição do método da "Semiologia Psicanalítica" foi Lévi-Strauss (1958/1974, 1958/2003) e a sua antropologia estrutural. LéviStrauss começará por evocar a linguística de Saussure, mais particularmente a equação deste autor que se tornou célebre, segundo a qual a linguagem é igual à língua mais a fala. Por um lado, Lévi-Strauss criticará esta linguística, opondo-se, mais precisamente, ao fato de Saussure, segundo ele, ter restringido sua abordagem ao arbitrário do signo, à dimensão relativa do social e dos sistemas particulares de signos (a língua e a fala). Com esta crítica, Lévi-Strauss justificará, por outro lado, sua proposição dos mitos como universais linguísticos, ausentes no pensamento de Saussure. Por outro lado, Lévi-Strauss justificará sua hipótese dos mitos como os reveladores do inconsciente humano, apoiando-se para tal em Freud e na psicanálise. O autor escreverá:

Pensamos particularmente na noção de mito e na noção de inconsciente. [...] De fato, inúmeros psicanalistas se recusarão a admitir que as constelações psíquicas que reaparecem à consciência do doente possam constituir um mito. [...]

[...] o objeto próprio dos mitos é de oferecer uma derivação a sentimentos reais, mas recalcados (Lévi-Strauss, 1958/2003, p. 233, 239). Ver passagem correspondente na edição francesa. (Lévi-Strauss, 1958/1974, p. 231, 237)

A partir, então, de Saussure (1916/1995a, 1916/1995b) e de Lévi-Strauss (1958/1974, 1958/2003), as duas primeiras inspirações de Bento (2007a) ao propor a "Semiologia Psicanalítica" tratada neste trabalho, chegou-se à noção de um método de pesquisa que estudaria os signos no seio de sua vida social, entendendo-se este "social" como algo que remete ao contexto dos ritos, dos costumes, dos mitos universais, dos escritos clássicos, etc. Um tal estudo permitiria o acesso aos sistemas de signos particulares (nas línguas) e universais (nos mitos), isto é, às linguagens reveladoras da natureza humana mais profunda, do psiquismo inconsciente do homem. Não se poderia ver aqui um modelo de método de pesquisa que, valorizando a linguagem enquanto legado social, daria importância a sua dimensão "escrita" (nos mitos, nas lendas, nos escritos clássicos, etc.), e, assim, funcionaria como justificativa da revisão de literatura? Por outro lado, a ideia de esta linguagem escrita revelar o psiquismo inconsciente do homem não permitiria supor que um tal método de pesquisa justificaria, em particular, a revisão de literatura em psicanálise? 
Entrando na psicanálise propriamente dita, Bento (2007a) encontrou a terceira inspiração de sua "Semiologia Psicanalítica" em Freud, particularmente em Totem e tabu. A hipótese de Bento (2007a) foi que esta obra constituiu a primeira "Semiologia Psicanalítica" de Freud (1913/1974), pois, ainda que o pai da psicanálise não tenha ali se utilizado desta expressão, pareceu ter efetivamente ali feito o que se entendeu como a prática da semiologia psicanalítica de dois signos: "Totem" e "Tabu". Estes dois signos foram de fato estudados por Freud (1913/1974) no seio da vida social. Assim fazendo, Freud pareceu realizar a semiologia (psicanalítica) dos dois termos (signos), uma ação correspondendo na prática à concepção hipotética de semiologia como "ciência que estude a vida dos signos no seio da vida social" (Saussure, 1916/1995b, p. 24).

Com base em Freud (1913/1974), Bento (2007a) chegou à seguinte conclusão: para manter uma ótica psicanalítica freudiana num estudo semiológico e fazer-se uma "Semiologia Psicanalítica", seria necessário situar a ênfase, como fez Freud em Totem e tabu, na análise radical dos universais da linguagem, estes reveladores da natureza humana mais profunda, do psiquismo inconsciente do homem, extraindo tais universais, num primeiro tempo, dos totens e mitos, mas também, num segundo tempo, dos tabus e das religiões. Pode-se questionar a esse respeito: um tal estudo demandando, de alguma maneira, o exame de "escritos", não pareceria, assim, justificar o método de revisão de literatura em psicanálise?

O ponto de vista estruturalista está presente tanto na linguística e na semiologia de Saussure (1916/1995a, 1916/1995b), quanto na "Semiologia Psicanalítica" proposta por Bento (2007a). A atitude estruturalista caracteriza-se pela valorização das relações entre os elementos de um sistema. Para explicar melhor esta ótica, podem-se citar as palavras de Dor, um autor pertencente ao campo da psicanálise:

A atitude estruturalista é uma estratégia de promoção de uma nova inteligibilidade que rompe com certas formas de pensar os objetos. [...] porquanto pôde pôr em evidência, com relação a elementos e objetos, sistemas de relações que não aparecem imediatamente entre eles. [...] Em particular, trata-se de renunciar a um certo tipo de descrição da natureza dos objetos, de suas qualidades, de suas propriedades específicas. Em contrapartida, o importante consiste em dar-se a possibilidade de fazer advir relações, aparentemente dissimuladas, que existem entre eles ou entre seus elementos (Dor, 1992, p. 22). Ver passagem correspondente na edição francesa. (Dor, 1985, p. 28)

A partir dessa citação pode-se entender que a linguística, tendo como objeto de estudo a língua, iria, então, explicá-lo como um sistema de signos. A inteligibilidade deste sistema decorreria da clareza com que se pudesse compreender as relações entre seus elementos, os signos. Já a semiologia 
que teria como objeto o signo, explicaria a inteligibilidade deste sistema com base nas relações entre seus elementos: o significante e o significado.

Para se pôr em evidência o nascimento da linguística estrutural após Saussure, assim como a dupla caracterização desta abordagem como ao mesmo tempo sincrônica e diacrônica, Dor escreve:

O ponto de vista estruturalista em linguística surgiu com a introdução da dimensão sincrônica no estudo da língua. Esta introdução do registro sincrônico, que devemos a F. Saussure, estipula que um tal estudo não pode ser reduzido a uma perspectiva puramente diacrônica, quer dizer, histórica. De fato, a história de uma palavra não permite dar conta de sua significação presente, pois esta significação depende do sistema da língua. Este sistema reside num certo número de leis de equilíbrio que estão na dependência direta da sincronia (Dor, 1992, p. 26). Ver passagem correspondente na edição francesa. (Dor, 1985, p. 32)

Compreende-se aqui que se trata em Saussure de uma linguística que valoriza uma sincronia diacrônica, se assim pode-se dizer, já que o sistema de signos (sincronia das palavras), que permite se "dar conta de sua significação presente" (p. 26), das relações entre seus próprios elementos (os signos), é valorizado, ao mesmo tempo em que se valoriza sua análise histórica, pois um "estudo não pode ser reduzido a uma perspectiva puramente diacrônica" (p. 26). Se se admite a hipótese da existência de uma analogia (raciocínio por analogia) entre a linguística e a semiologia de Saussure pelo fato de ambas possuírem uma função estruturalista que as aproxima no estudo de seus respectivos objetos - a língua, um sistema de signos objeto da linguística; e o signo, objeto da semiologia e, também, da linguística, já que esta, ao estudar a língua, acaba por se ocupar do sistema de signos que constitui a língua -, não se poderia esperar encontrar em Saussure uma semiologia, ela também, ao mesmo tempo, sincrônica e diacrônica? Não é encontrada a este propósito nenhuma indicação diretamente enunciada no único e pequeno subitem que Saussure (1916/1995a, p. 32-35) consagra à semiologia nesta obra que trata essencialmente da linguística. Não seria necessário então procurar neste autor indicações indiretas que evocassem esta semiologia ao mesmo tempo sincrônica e diacrônica? Se se considera que a semiologia, no Curso de linguística geral de Saussure, encontrava-se ainda em gestação, não seria então natural resignar-se em apenas poder supor esta semiologia com base nas analogias entre esta e a linguística, com base nas pistas indiretas que Saussure teria deixado?

Feitos esses esclarecimentos introdutórios sobre alguns dos principais fundamentos teóricos do método semiológico e, particularmente, da "Semiologia Psicanalítica", pode-se passar ao último item deste trabalho para abordar o método de pesquisa da hipótese das paixões "tóxicas": do raciocínio por analogia à semiologia psicanalítica. 


\section{O método de pesquisa da hipótese das paixões "tóxicas": do raciocínio por analogia à semiologia psicanalítica}

Como seu título sugere, o objetivo deste item é utilizar os fundamentos teóricos dos dois métodos de pesquisa - o raciocínio por analogia e o método semiológico - introduzidos nos itens anteriores para justificar a aplicação de ambos na abordagem da hipótese das paixões "tóxicas". Pretendese com esta aplicação equacionar uma formulação desta hipótese de acordo com tais métodos; e estruturar um plano de estudo teórico desta hipótese adequado a esta formulação.

Parte-se aqui do pressuposto hipotético de existência de uma analogia qualitativa de funções entre o método do raciocínio por analogia e o moderno método semiológico. Mais precisamente, acredita-se hipoteticamente que o método do raciocínio por analogia de Aristóteles possui funções semelhantes, mas não idênticas, àquelas funções do método semiológico, a saber:

$1^{\mathrm{a}}$ - A função de descoberta de semelhanças funcionais escondidas do método do raciocínio por analogia é perfeitamente adequada ao objetivo desta pesquisa de chegar aqui a uma semiologia "psicanalítica" e, assim, valorizar o inconsciente, este igualmente escondido, tal como são escondidas estas funções semelhantes encontradas nas analogias qualitativas reveladas pelo raciocínio por analogia de Aristóteles (1972) e de Aristóteles (1992)?

Considerando que essa função de descoberta de uma relação entre termos ou signos é semelhante ou comum aos métodos do raciocínio por analogia e da semiologia psicanalítica, não se poderia aproximá-los, supondo-se, então, que eles são análogos? Em outras palavras, seria o método do raciocínio por analogia análogo a este método semiológico, já que ambos os métodos possuem uma função semelhante de descoberta de função ou de relação escondida entre termos ou signos? Neste caso particular de aproximarem-se termos que possuem função semelhante, não se poderia de fato caracterizar esta "semiologia psicanalítica" buscada nesta pesquisa como análoga, como seguindo o mesmo modelo do raciocínio por analogia de funções qualitativas - semelhantes, mas não idênticas - em Aristóteles (1972) e em Aristóteles (1992)?

$2^{\mathrm{a}}$ - A função de generalização, de formação de conceitos, de teorização sistemática do raciocínio por analogia não parece ser semelhante à função do método semiológico de revisão de literatura com base no exame dos escritos clássicos para construir a história da relação entre signos, o que, no caso particular desta pesquisa, resultaria na construção de um corpo teórico, de um conjunto de fundamentos teóricos sobre a noção de "paixões tóxicas"? Se sim, parece que também esta segunda função do método do raciocínio por 
analogia - a função de generalização, de formação de conceitos, de teorização sistemática - o aproximaria do método semiológico, permitindo-se supor a existência de uma analogia qualitativa de funções entre os dois métodos.

Finalmente, parece que se podem aproximar os métodos do raciocínio por analogia e semiológico, supondo-os como análogos, porque uma tal aproximação já foi feita com sucesso, ainda que não direta e claramente enunciada, por outros autores de renome, entre os quais podem-se citar Saussure (1916/1995a, 1916/1995b), Freud (1913/1974) e Lacan (1966, 1966/ 1998), conforme já foi demonstrado em outras oportunidades, ainda que implicitamente sugerido nas entrelinhas do relato destas outras pesquisas, em Bento (2006b, 2007a, 2007c).

Além disso, pode-se encontrar na literatura constituída pelos autores críticos do campo da lógica e da epistemologia um parecer favorável quanto ao rigor, tanto metodológico, quanto teórico, deste paralelo feito entre o método do raciocínio por analogia e o método semiológico, desta suposição de uma analogia entre os dois métodos. Como exemplo de tais autores, podese citar Coster (1978), que desenvolve um trabalho mais específico do que aqueles dois autores acima citados para tratar da analogia - Lalande (1926/ 1996, 1926/1993); Secretan (1984); e Dorolle (1949) -, consagrado ao estudo de "A analogia (lógica de semelhança de funções) em ciência humanas" (tradução nossa).

Coster (1978) evocará inicialmente a origem do modelo do raciocínio por analogia no Timeu de Patão (1977) - ver edição francesa em Platão (1969) - e, em seguida, na Ética a Nicômaco de Aristóteles (1972) - ver edição francesa em Aristóteles (1992) -, distinguindo três tipos de analogias: $1^{\mathrm{a}}$ discursiva, $2^{\mathrm{a}}$ metodológica, e $3^{\mathrm{a}}$ teórica. A função da primeira, apenas no nível da linguagem, é descrita como conceitual, didática e retórica. A segunda é vista como "instrumento de invenção suscetível de introduzir a pesquisa numa via determinada" (p. 26; tradução nossa), estando, assim, ligada à função heurística. Finalmente, a analogia teórica é situada no campo de uma busca de parentesco que une as semelhanças, de uma busca de construção sistemática de modelos que extraem este parentesco real de dois sistemas.

Será apenas no terceiro capítulo de sua obra que Coster (1978) abordará aquilo que interessa destacar agora. O autor tratará, então, da homologia estrutural (que remete ao estruturalismo) como caso particular da analogia teórica e a definirá, baseando-se para tal em Lucien Goldmann, como "uma busca sistemática de correspondências entre duas manifestações paralelas de uma mesma realidade" (p. 47; tradução nossa), diferenciando-a, assim, da analogia pelo fato de ela implicar três dimensões - das quais, duas procedem de uma mesma terceira -, enquanto a analogia concerne a apenas duas dimensões - uma se encaixando na outra. Se, por um lado, o autor 
considera que uma tal distinção não possui interesse para a pesquisa, já que a homologia estrutural reduz-se à analogia, por outro lado, o autor vai valorizar "a ambição de extrair uma ligação entre variáveis em jogo com base em uma descoberta sistemática de suas semelhanças 'estruturais'" (p. 51) e "a busca de correspondências que não se parecem mais simplesmente com uma metodologia, porque ela culmina diretamente num projeto teórico" (p. 51-52; traduções nossas). É, então, neste momento, que Coster (1978) fará uma referência indireta ao domínio da semiologia em relação ao raciocínio por analogia, pois citará Barthes (1985, 1985/2001), em "Introdução à análise estrutural das narrativas", no livro A aventura semiológica, para destacá-lo como um autor em quem se pode encontrar uma proposição rigorosa de raciocínio por analogia, em uma perspectiva de analogia tanto metodológica, quanto teórica.

Tendo-se revisto brevemente a literatura tratando dos métodos de pesquisa do raciocínio por analogia e semiológico, assim como da justificativa da passagem do primeiro para o segundo por se tratarem de métodos análogos, isto é, possuidores de funções semelhantes, embora não idênticas, o que permitiria aproximá-los por meio de um raciocínio por analogia qualitativa, pode-se agora passar à discussão da aplicação destes métodos na hipótese das paixões "tóxicas" - isto é, na hipótese da existência da função do excesso narcísico, semelhante, mas não idêntica, nas paixões e nas toxicomanias - para equacionar uma formulação desta hipótese de acordo com tais métodos; e estruturar um plano de estudo teórico desta hipótese adequado a esta formulação.

Ora, Aristóteles, como se viu acima referido por Dorolle (1949), foi o primeiro a propor o raciocínio por analogia em torno do modelo da igualdade de funções na proporção geométrica (A : B :: C : D), generalizando-o em seguida para outros domínios quando evocou o modelo da semelhança qualitativa de funções (Pulmão : Ar :: Brânquias : Água). Sendo estas analogias por semelhança de funções vistas pelos epistemólogos como tão precisas quanto as analogias por igualdade de funções nas proporções geométricas, parece que seria possível tomar emprestado de Aristóteles este modelo da semelhança de funções para pensar a hipótese das paixões "tóxicas" no campo da semiologia.

Mais precisamente, parece ser possível pensar a paixão e a toxicomania enquanto signos (objetos da semiologia) que possuem uma analogia de função qualitativa escondida, inconsciente, no excesso narcísico. Partindose, então, da proposição de Aristóteles sobre o raciocínio por analogia na igualdade de funções da proporção geométrica ( $\mathrm{A}$ : B :: C : D) em direção ao método semiológico, para pensar a hipótese das paixões "tóxicas", poderse-ia chegar a uma proposição assim esquematizada: 


$$
\mathrm{A} / \mathrm{B} \quad:: \mathrm{C} / \mathrm{D} \quad \text { é análogo a } \quad \mathrm{S} 1 / \mathrm{s} 1 \quad:: \mathrm{S} 2 / \mathrm{S} 2
$$

em que "S" é o significante; "s" é o significado; "1" é o primeiro signo - paixão -, constituído por um determinado significante S1 e por seu respectivo significado s1; e "2" é o segundo signo - toxicomania, ou adicção, ou tóxico, ou droga -, também constituído por um determinado significante S2 e por seu respectivo significado s2.

Essa segunda analogia proposta no esquema acima parece ser, na terminologia de Coster (1978), uma homologia estrutural implicando, então, três dimensões, num duplo projeto ao mesmo tempo metodológico e teórico. Estas dimensões seriam:

$1^{\circ}$ - A dimensão do primeiro signo (S1/s1) - a paixão;

$2^{\circ}$ - A dimensão do segundo signo (S2/s2) - a toxicomania, ou a adicção, ou o tóxico, ou a droga; e

$3^{\circ}$ - A dimensão da função escondida, semelhante, mas não idêntica, nos dois signos - o excesso do narcisismo inconsciente.

Assim esquematizada a hipótese das paixões "tóxicas", seu plano de estudo teórico estaria implicitamente determinado, implicando a pesquisa de cada uma dessas três dimensões respectivamente em três tempos, a saber:

$1^{\circ}$ - O tempo do estudo da semiologia psicanalítica da paixão e seus sentidos adictivo e tóxico, estudo este discutido com base no raciocínio por analogia relacionando a paixão, de um lado, com a toxicomania, a adicção, o tóxico e a droga, de outro;

$2^{\circ}$ - O tempo do estudo da semiologia psicanalítica das toxicomanias e seu sentido passional, estudo este discutido com base no raciocínio por analogia relacionando a toxicomania, a adicção, o tóxico e a droga, de um lado, com a paixão, de outro; e

$3^{\circ}$ - O tempo do estudo da semiologia psicanalítica do narcisismo em Freud e as paixões tóxicas a partir de e após Freud. Partir-se-ia aqui do pressuposto hipotético de que na teorização freudiana sobre o narcisismo existiriam indicações implicitamente sugeridas a respeito da teorização sobre as paixões "tóxicas". Mais precisamente, partir-se-ia num primeiro momento do narcisismo freudiano para levantar-se com base nele hipóteses sobre as paixões "tóxicas", hipóteses estas que seriam verificadas e discutidas num segundo momento com base na revisão da literatura psicanalítica pós-freudiana tratando das paixões e das toxicomanias (ou das adicções, ou do tóxico, ou da droga).

O procedimento metodológico desse plano valorizaria a dupla perspectiva de um estudo ao mesmo tempo sincrônico e diacrônico. Desta forma, seria possível adequar aos modelos metodológicos do raciocínio por analo- 
gia, tal como descrito por Dorolle (1949), e semiológico, tal como encontrado em Saussure (1916/1995a, 1916/1995b), Freud (1913/1974) e Lacan (1966, 1966/1998), este modelo semiológico em consonância com o que se discutiu acima de forma introdutória e, com maior detalhamento, em outras oportunidades em Bento (2006b, 2007a, 2007c). Significa dizer que se pretende valorizar na dimensão sincrônica a expressão atual dos signos explicados com base nas relações mútuas entre seus respectivos significantes e significados. Mas também se daria destaque à dimensão diacrônica, realizando-se uma construção da história dos signos a partir de suas origens. Será assim que as histórias da paixão, da toxicomania e do narcisismo em Freud serão narradas neste estudo agora vislumbrado em forma de plano, dando-se destaque principalmente ao universo semântico originário - dos três signos, que são a paixão, a toxicomania e o narcisismo -, tão valorizado pelo método semiológico, de natureza e função essencialmente estruturalistas. Espera-se, desta forma, construir um corpo teórico constituído pelos fundamentos teóricos psicanalíticos, em debate interdisciplinar, da hipótese das paixões "tóxicas".

\section{Considerações finais}

Acredita-se que o presente estudo teórico tenha atingido seu objetivo principal. Pois, de fato, discutiram-se aqui, em nível introdutório, os seguintes pontos: $1^{\circ}$ Alguns fundamentos teóricos do método de pesquisa do raciocínio por analogia; $2^{\circ}$ Alguns fundamentos teóricos do método de pesquisa semiológica; e $3^{\circ} \mathrm{O}$ método de pesquisa da hipótese das paixões "tóxicas": do raciocínio por analogia à semiologia psicanalítica. A dupla finalidade deste terceiro e último ponto também foi atingida. Pois, por um lado, equacionou-se aqui uma formulação desta hipótese de acordo com estes métodos; e, por outro, estruturou-se um plano de estudo teórico de caráter psicanalítico, em debate interdisciplinar, adequado a esta formulação, a ser executado em outras investigações com base na aplicação destes métodos na pesquisa desta hipótese das paixões "tóxicas".

Quanto às limitações do presente estudo, pode-se dizer que esta pesquisa não discutiu as justificativas da hipótese da paixões "tóxicas", não se aprofundou na abordagem dos fundamentos teóricos dos métodos desta investigação, nem tratou das aplicações destes métodos nas paixões "tóxicas". Isto ocorreu porque estes não eram os objetivos deste trabalho e, também, porque uma tal empreitada extrapolaria os limites espaciais do presente estudo, acabando por implicar outros artigos. Quanto às justificativas da hipótese em questão, pode-se remeter os leitores interessados a Bento (1996). No que concerne especificamente aos fundamentos teóricos 
do método semiológico utilizado nesta investigação das paixões "tóxicas", deve-se informar que estes já foram discutidos em outras oportunidades, podendo-se, então, remeter os leitores interessados à leitura de Bento (2006b, 2007a, 2007b). Já os leitores interessados em aprofundar-se na aplicação do método semiológico em pesquisas teóricas sobre as toxicomanias, as adicções e as paixões "tóxicas", com ênfase na discussão da hipótese das paixões "tóxicas" tal como enunciada neste estudo - isto é, aquela hipótese que afirma serem as paixões semelhantes, mas não idênticas, às toxicomanias; ou, mais precisamente, que existe analogia qualitativa da função do excesso narcísico, semelhante, mas não idêntica, nas paixões e as toxicomanias -, deverão ler Bento (1993, 1994a, 1994b, 1995, 1996, 1998, 1999, 2003, 2006a, 2007c, 2008).

BENTO, Victor Eduardo Silva. Introduction to the research method of 'toxic' passions: from reasoning by analogy to psychoanalitical semiology. Trans/Form/Ação. São Paulo, v.32(1), 2009, p.175-192.

- ABSTRACT: We have made a search of critical revision about the literature in epistemology. We started from the "toxic" passions hypothesis, that is, from the assumption according to which there is a functional analogy between passions and toxicomanias: the function of the excess of narcissism, similar, but not identical, in both of them. The objective was to introduce the theoretical basis of the qualitative search method of this hypothesis, starting from the analogical reasoning to psychoanalytical semiology. More exactly, we intended to introduce the discussion about the theoretical foundations of these methods, which we consider analogous, with a double purpose: $1^{\text {st }}$ to formulate the "toxic" passions hypothesis according to these methods; and $2^{\text {nd }}$ - to make a theoretical plan of study in psychoanalysis, result of discussions among other interdisciplinary approaches. Such a plan, elaborated according to this formulation, could be executed later through the application of these methods to the search of this hypothesis.

- KEYWORDS: Epistemology; qualitative search method; analogical reasoning; psychoanalytical semiology; toxic passions.

\section{Referências bibliográficas}

ARISTÓTELES. Ética a Nicômaco. São Paulo: Abril Cultural, 1972. Éthique à Nicomaque. Paris: Librairie Générale Française, 1992.

BARTHES, R. Introduction à l'analyse structurale des récits. In: . L'aventure sémiologique. Paris: Seuil, 1985, p. 167-206.

Introdução à análise estrutural das narrativas. In: . A aventura semiológica. São Paulo: Martins Fontes, 2001, p. 103-152. 
BENTO, V. E. S. Tóxico, droga, toxicomania e adicção: uma introdução à etimologia segundo uma ótica psicanalítica. Jornal Brasileiro de Psiquiatria, v. 42, n. 7, 1993, p. 373-380.

Leonardo da Vinci e uma lembrança da sua infância: considerações sobre o narcisismo em Freud e sobre a paixão amorosa "tóxica" a partir de Freud. Temas: Teoria e Prática do Psiquiatra, v. 24, n. 47, 1994a, p. 94-113.

Três ensaios sobre a teoria da sexualidade: considerações sobre o conceito de narcisismo em Freud (1905) e sobre a paixão amorosa "tóxica" a partir de Freud. Revista ABP-APAL, v. 16, n. 4, 1994b, p. 154-164.

O presidente Schreber, um caso de paranóia: considerações sobre o narcisismo em Freud (1911) e sobre a paixão amorosa "tóxica" a partir de Freud. Informação Psiquiátrica, v. 14, n. 1, 1995, p. 27-35.

La passion amoureuse "toxique": une approche psychanalytique à partir de la sémiologie et du narcissisme chez Freud, 1996. 472 p. Tese de Doutorado em Psicopatologia Fundamental e Psicanálise. U. F. R de Sciences Humaines Cliniques, Laboratoire de Psychopathologie Fondamentale et Psychanalyse. Paris: Universidade de Paris 7, 1996.

. O narcisismo em Freud e paixão "tóxica" a partir de Freud. Psicologia em Estudo, v. 3, n. 2, 1998, p. 1-37.

Pour introduire une "sémiologie psychanalytique" de la notion de "toxicomanie" dans l'approche médicale. Interventions: Revue de l'ANIT - Association Nationale des Intervenants en Toxicomanie, n. 68, 1999, p. 16-22.

O narcisismo em Freud e a paixão "tóxica" a partir de Freud. In: BAPTISTA, M., CRUZ, M. S., \& MATIAS, R. (Orgs.). Drogas e pós-modernidade: prazer, sofrimento e tabu. Rio de Janeiro: EdUERJ, 2003. v. 1, p. 147-172.

. Tóxico e adiç̧ão comparados a paixão e toxicomania: etimologia e psicanálise. Psicologia USP, v. 17, n. 1, 2006a, p. 181-206.

Seria a semiologia de Saussure fundamento e justificativa para o método de pesquisa de revisão de literatura em psicanálise? Estudos de Psicologia, v. 23, n. 4, 2006b, p. 407-423.

Totem e Tabu: uma "semiologia psicanalítica" em Freud? Estudos de PsiCologia, v. 24, n. 3, 2007a, p. 397-406.

Existiria uma "semiologia psicanalítica" em Lacan? Aletheia, n. 25, 2007b, p. 177-190.

Para uma semiologia psicanalítica das toxicomanias: adicções e paixões tóxicas no Freud pré-psicanalítico. Revista Mal-estar e Subjetividade, v. 7, n. 1, 2007c, p. 89-121.

Para uma semiologia psicanalítica da paixão na Antiguidade Grega e seus sentidos adictivo e tóxico. Psicologia USP, v. 19, n. 2, 2008, p. 129-158.

COSTER, M. de. L'analogie en sciences humaines. Paris: PUF, 1978.

DOR, J. Introduction à la lecture de Lacan. Paris: Denoël, 1985.

Introdução à leitura de Lacan. 3. ed. Porto Alegre: Artes Médicas, 1992.

DOROLLE, M. Le raisonnement par analogie. Paris: PUF, 1949. 
FREUD, S. Totem e tabu (1913). In: Edição standard brasileira das obras psicológicas completas de Sigmund Freud. Rio de Janeiro: Imago, 1974. v. 13, p. 11-191.

LACAN, J. L'instance de la lettre dans l'inconscient ou la raison depuis Freud. In: Écrits. Paris: Seuil, 1966. p. 493-528.

A instância da letra no inconsciente ou a razão desde Freud (1966). In: Escritos. Rio de Janeiro: Jorge Zahar, 1998. p. 496-533.

LALANDE, A. Vocabulaire technique et critique de la philosophie (1926). 3. ed. Paris: Quadrige/PUF, 1993. 2 v.

. Vocabulário técnico e crítico da filosofia (1926). 2. ed. São Paulo: Martins Fontes, 1996.

LÉVI-STRAUSS, C. Anthropologie structurale (1958). Paris: Plon, 1974.

Antropologia estrutural (1958). 6. ed. Rio de Janeiro: Tempo Brasileiro, 2003.

PLATÃO. Timée. In: Sophiste, Politique, Philèbe, Timée, Critias. Paris: Garnier/Flammarion, 1969, p. 399-469. . Timeu. Belém: Editora da UFPA, 1977.

SAUSSURE, F. de. Cours de linguistique générale (1916). Paris: Payot \& Rivages, 1995a. Curso de linguística geral (1916). São Paulo: Cultrix, 1995b.

SECRETAN, P. L'analogie. Paris: PUF, 1984. 